\title{
Availability and Utilization of World Health Organization Recommended Priority Life-Saving Medicines for Under Five-Year-Old Children in Gondar Town, Ethiopia: A Cross-Sectional Study
}

\author{
Alem Endeshaw \\ Woldeyohanins (1D) \\ Asmamaw Emagn Kasahun (D) \\ Chilot Abiyu Demeke (D) \\ Zemene Demelash Kifle (D) ${ }^{2}$ \\ 'Department of Pharmaceutics and Social \\ Pharmacy, School of Pharmacy Gondar, \\ University of Gondar-College of Medicine \\ and Health Sciences, Gondar, Ethiopia; \\ ${ }^{2}$ Department of Pharmacology, School of \\ Pharmacy Gondar, University of Gondar- \\ College of Medicine and Health Sciences, \\ Gondar, Ethiopia
}

Background: Globally, more than eight million under-five children die every year because of diseases that could be treated or prevented with drug therapy. Thus, this study aimed to evaluate the utilization and availability of the World Health Organization (WHO) suggested priority life-saving medicines for under-five-year-old children in Gondar town.

Methods: Institutional-based cross-sectional survey was conducted from March 2020 to May 2020 in public health centers of Gondar town. Data entry and validation were performed in EpiData 3.1 and exported to SPSS version 20 for descriptive analysis like frequency, percentage, mean, standard deviation, and median.

Results: The availability of zinc phosphate and oral rehydration salt for the diarrheal cases was $57.14 \%$ and $85.71 \%$, respectively. The availabilities of amoxicillin dispersible tablet and gentamicin injection for the treatments of pneumonia cases were $71.43 \%$ and $42.85 \%$, respectively, and the availability of paracetamol tablet was high $(85.71 \%)$. The availabilities of artemether/lumefantrine tablet and artesunate rectal were ranged between fairly high $(57.1 \%)$ to very low $(28.5 \%)$, respectively, and the availabilities of zidovudine/lamivudine/ nevirapine-based antiretroviral regimen was $100 \%$, a utilization for this regimen was high $(96.29 \%)$. Two $(3.70 \%)$ of the surveyed cases were utilized lopinavir/ritonavir-based regimen. The utilization of priority medicines was low for pain management and pneumonia which was $18.5 \%$ and $48.18 \%$, respectively.

Conclusion: The study concluded that medicine was not consistently available throughout public health centers in Gondar town. Thus, this finding suggests the integration of WHOrecommended life-saving priority medicines into the essential drug management systems and health unit logistics to raise their utilization and availability.

Keywords: availability, utilization, priority medicines, Gondar, Ethiopia

\section{Introduction}

Correspondence: Alem Endeshaw Woldeyohanins

Department of Pharmaceutics and Social Pharmacy, School of Pharmacy Gondar, University of Gondar-College of Medicine and Health Sciences, P.O. Box 196,

Gondar, Ethiopia

Tel +251920292874

Fax +25I-58-II4I 240

Email aleend2008@gmail.com;

Alem.Endashaw@uog.edu.et
Globally, more than eight million under-five children die every year because of diseases that could be treated or prevented with drug therapy. ${ }^{1}$ Many caretakers and parents have not enough money for consultations and treatment looked for by their children, the problem was significantly higher in developing countries like Africa and Asia. ${ }^{1,2}$

This resulted in developing countries, particularly Africa is a region where the highest Under-5 mortality rate is observed where one child in thirteen dying before her/his 5th birthday, which is the worst. Most mortality-causing diseases are 
manageable if adequate pharmaceuticals are available and appropriately used. However, crosscutting challenges like limited availability, use disparities, and weak supply chain management practices continue to minimize their impact. $^{3,4}$

Less than five-year-old children mortality rate is the foremost pointer of the overall development in countries and the level of child health which shows the population quality of life, as measured by life expectancy. Most causes of under-five children's deaths in developing countries are because of infectious illnesses. Childhood survival is increased due to improvements in primary healthcare systems, coupled with the increasing accessibility of vaccines. However, further interventions are needed to decrease childhood mortality. 5,6

Poor availability of right medications with right dosage form for the right persons, the health care professionals may be forced to utilize medications of manipulated dosage forms. This practice results in administration errors such as errors in dilution, dosage calculation, and intravenous drips running. Moreover, the use of manipulated adult dosage forms can bring unwanted outcomes, treatment failure, and may go to the extent of losing the child..$^{7-9}$ most of published studies also suggested that better availabilities and rational utilizations antibiotic treatment and immunization can significantly reduces deaths. ${ }^{10}$

Despite the introduction of priority medicines for children under five at the global level, research conducted in the Tigray region of Ethiopia demonstrated low availability of the medicines in public health facilities (The average availability of the most expensive drugs was in the range $0-4.5 \%$, while the lowest-priced medicines were in the range $10.7-75 \%) .{ }^{11}$ In Uganda's public health facilities, life-saving priority drugs for pneumonia and malaria are scarce and underutilized. Priority drugs for diarrhea and sepsis, on the other hand, are readily available and frequently prescribed by health professionals. ${ }^{1}$ Little is known regarding the availability and utilization of the priority medicines for treating under five-year-old children in public health facilities in Ethiopia. Thus, this study aimed to assess the utilization and availability of the WHO suggested life-saving priority drugs for fewer than five children at public health centers, Gondar town, Ethiopia.

\section{Methods}

\section{Study Design and Setting}

An institutional-based cross-sectional survey was done at Gondar town health center; Gondar town is placed in the
North Gondar zone of the state of Amhara regional, which is placed at $737 \mathrm{~km}$ far from Addis Ababa which is the capital city of Ethiopia, and far $180 \mathrm{~km}$ in the north direction, of Bahir Dar (Capital of Amhara Region). There are eight public health centers in Gondar town; seven of them can provide Antiretroviral treatment (ART) serves. The study was conducted from March 2020 to May 2020.

\section{Source Population and Study Units}

All health centers, and all medications were source population of the study. Selected health centers, WHO suggested priority lifesaving medicines and patient cards were taken as the study unit.

\section{Inclusion and Exclusion Criteria}

All eight cities (Health centers-primary care unit in Ethiopia) are not included in the study, since one health center (Alage Health center) was excluded from the study. Because this health center did not provide antiretroviral treatment, antiretroviral drugs were one of the world health organizationsrecommended priority medicine for children under the age of five. So that we incorporated only seven health centers that can provide service for all the priority diseases. Sepsis was also left out from the current study since there is no sepsis management protocol in Ethiopia health centers.

\section{Sampling Procedures and Sample Size Determination}

Nineteen WHO-suggested priority life-saving medicines for malaria, HIV, vitamin A deficiency diarrhea, pain management, and pneumonia were considered. Amoxicillin 250 or $500 \mathrm{mg}$ dispersible tablets/capsules, Ampicillin 250 or $500 \mathrm{mg}$ powder for injection, Gentamicin sulfate $40 \mathrm{mg} / \mathrm{mL}$ in $1 \mathrm{~mL}$ Injection, and Ceftriaxone powder $1 \mathrm{gm} / 50 \mathrm{~mL}$, or $2 \mathrm{gm} / 50 \mathrm{~mL}$ powder injection were included for pneumonia. For malaria, Artemether/lumefantrine $20 \mathrm{mg} / 120 \mathrm{mg}$ tablet, Artesunate $110 \mathrm{mg} /$ via injection, and Artesunate $100 \mathrm{mg}$ rectal capsule. For diarrhea, Oral Rehydration salt (ORS) and Zinc Phosphate $20 \mathrm{mg}$ dispersible tablet were comprised. Vitamin A for vitamin A deficiency and Paracetamol dispersible tablets were considered for pain management, even though WHO suggested morphine as priority medicines for pain management we found that the health centers did not manage morphine at all. ${ }^{12,13}$ WHO list does not stipulate medication HIV/ADIS management; instead, it endorses referring to country-specific lists. ${ }^{14}$ Lamivudine (3TC), Zidovudine (AZT), Abacavir (ABC), Efavirenz (EVF), Lopinavir/ritonavir (LPV/r), 
Table I WHO Suggested Priority Diseases and Medications Which Were Considered for Study at Public Health Centers of Gondar Town by 2021

\begin{tabular}{|c|c|c|}
\hline S.N & $\begin{array}{l}\text { Priority Diseases of Children Under the Age } \\
\text { of Five }\end{array}$ & Priority Drugs for Children Under the Age of Five \\
\hline \multirow[t]{2}{*}{ I } & \multirow[t]{2}{*}{ Diarrhea } & Oral rehydration salt Sacket \\
\hline & & Zinc Phosphate $20 \mathrm{mg}$ dispersible tablet \\
\hline 2 & Pain & Paracetamol 100mg dispersible tablet \\
\hline \multirow[t]{4}{*}{3} & \multirow[t]{4}{*}{ Pneumonia } & Amoxicillin $250 \mathrm{mg}$ dispersible tablet or $500 \mathrm{mg}$ \\
\hline & & Ampicillin 250 or $500 \mathrm{mg}$ powder for injection \\
\hline & & Gentamicin sulfate $40 \mathrm{mg} / \mathrm{mL}$ in I mL Injection \\
\hline & & Ceftriaxone powder I gm $/ 50 \mathrm{~mL}$, or $2 \mathrm{gm} / 50 \mathrm{~mL}$ powder for injection \\
\hline \multirow[t]{3}{*}{4} & \multirow[t]{3}{*}{ Malaria } & Artemether/lumefantrine $20 \mathrm{mg} / 120 \mathrm{mg}$ tablet \\
\hline & & Artesunate $110 \mathrm{mg} /$ via injection \\
\hline & & Artesunate $100 \mathrm{mg}$ rectal capsule \\
\hline 5 & Vitamin A Deficiency & Vitamin A: 100,000 IU or 200,000 IU strength capsules \\
\hline \multirow[t]{7}{*}{6} & \multirow[t]{7}{*}{ Antiretroviral infection } & $\mathrm{AZT}+3 \mathrm{TC}+\mathrm{NVP} 3 \mathrm{TC} 30 \mathrm{mg}+\mathrm{AZT} 60 \mathrm{mg}+\mathrm{NVP50mg}$, dispersible tablet \\
\hline & & $A B C+3 T C 3 T C 60 m g+120 m g A B C$, scored and dispersible tablet \\
\hline & & AZT+3TC 3TC30mg+AZT60mg, dispersible tablet \\
\hline & & NVP oral syrup, $50 \mathrm{mg} / 5 \mathrm{~mL}(10 \mathrm{mg} / \mathrm{mL})$ \\
\hline & & 3 TC $30 \mathrm{mg}$ \\
\hline & & LPV/r LPVI00mg+Ritonavir25mg) \\
\hline & & EVF $200 \mathrm{mg}$, scored tablet. Or $50 \mathrm{mg}$, tablet or capsule \\
\hline
\end{tabular}

Nevirapine (NVP). Therefore, 3TC 30mg + AZT60mg+ NVP $50 \mathrm{mg}$, dispersible tablet, 3TC60mg $+120 \mathrm{mg} \mathrm{ABC}$, scored and dispersible tablet, 3TC30mg+AZT60mg, dispersible tablet, NVP oral syrup, $50 \mathrm{mg} / 5 \mathrm{~mL}(10 \mathrm{mg} / \mathrm{mL})$, 3TC $30 \mathrm{mg}$, LPV/r (LPV100 mg + r 25mg), EVF $200 \mathrm{mg}$, scored tablet, or $50 \mathrm{mg}$, tablet, or capsule were included in the study (Table 1). ${ }^{15}$

Patient cards were assessed to determine the utilization pattern of WHO-recommended priority medications. Patient cards with the disease of interest were identified based on their diagnosis's registration number; then, chart review was done to assess medications prescribed for the disease of interest and evaluated against WHO recommendations. The sample size was calculated based on a single population proportion formula with the assumption of $50 \%$ as a proportion (p), at $95 \%$ confidence level and Margin of error (d) $=5 \%$. Where $\mathrm{N}$ is the sampling frame, $\mathrm{n}$ is the sample size obtained from the general formula, and $\mathrm{nf}$ is the adjusted final sample size (4244). The final sample size was then scattered according to the number of cases per facility. Card numbers were obtained from the register book to attain the compulsory patient document. Last year patient cards were considered for sampling.

$$
n=\frac{\left(Z_{\alpha 1 / 2}\right)^{2} * p(1-p)}{d^{2}}=384
$$

The incidences of the WHO priority illnesses for underfive children for the past one year were obtained from the Gondar town health bureau before computing the final sample size, and 4244 attendants were identified; therefore, the sampling frame was 4244 , which is beneath 10,000 so that the sample obtained from the general formula (384) was adjusted to obtain the final sample size.

$$
n f n /[1+((n-1) / N)]=353
$$

Where $\mathrm{N}$ is the total population size which is $4244, \mathrm{n}$ is the sample size obtained from the general formula, and $\mathrm{nf}$ is the adjusted final sample size. The final sample size was then scattered proportionally. A total of 378 patient charts were 
taken; then, 54 patent cards were taken from each facility and 9 charts for each case were selected randomly from each (7 health centers). Therefore, a total of 54 charts for each case were selected to assess utilization.

\section{Data Collection Procedures}

International Development (USAID) delivery guideline was used to prepare the data collection regarding availability. ${ }^{16}$ Checklists and questionnaires were used for data collection. Several published articles were reviewed to prepare the data collection tool for assessing the utilization practices. The questionnaires contain two sections; the 1st section was comprised of questions concerning the availability of drugs on the day of the visit, the 2nd section was comprised of questions related to the utilization of life-saving medicines. The availability on the day of the visit was determined by using physical verification and percentage availability was calculated as the proportion of facilities with the WHO suggested priority lifesaving drugs. The sampled patient cards of 1 year were crisscrossed to assess the utilization practice. The data collectors were appropriately skilled in the data collection tool before data collection. The collected data were cleared and checked every day for completeness and consistency before processing. During data gathering, two trained health professionals were recruited and supervised by two Master of Science (MSc) graduate health professionals. Finally, the completeness and fulfillment of all questions were checked by the principal investigator and data collectors.

\section{Data Entry and Analysis}

Data validation and entry were conducted using EpiData 3.1 and transferred to Statistical Package Software for Social Sciences version 20 for Descriptive analysis. Availability was determined by the number of the WHO suggested priority lifesaving drugs for malaria, pain management, diarrhea, human immune virus/acquired immune deficiency (HIV/AIDS), pneumonia, and vitamin A deficiency among under-five children as a percentage of the total number of surveyed facilities. Likewise, the utilization was determined as the percentage of personal medicines prescribed for specific illnesses set in the patient cards. The results were described using text tables and figures.

The following cutting point has been used for describing the availability such as availability very low when $<30 \%$, availability low 30-49\% low, availability fairly high $50-$ $80 \%$ fairly high, and availability high $>80 \%$ high. $^{17}$

\section{Results}

\section{Availability of Lifesaving Medicines for Under - Five-Year-Old Children}

The finding of the current study revealed overall availability of life-saving medicines was $62.9 \%$ (range $28.5 \%$ to $100 \%$, standard deviation $=1.32$ ). This has shown that the overall availability of medicines at a different public health center in the study area was consistent throughout the sectors.

Availability of priority medicines for diarrheal cases was high for ORS which is $85.7 \%$ and Zinc phosphate dispersible tablets were fairly high 4 (57.14\%) among surveys of the health centers at the time of visit. Availability of paracetamol dispersible tablet for pain management was high which was $6(85.7 \%)$, the study facilities are not equipped to manage morphine, because of this availability of Morphine was not assessed (Table 2).

The availability of medicines for Pneumonia cases was fairly high (57.14\%) for both Ceftriaxone and Ampicillin Injection, availability of Amoxicillin and Gentamicin was high (71.43\%) and low (42.85\%), respectively (Table 1). Availability of Vitamin A was fairly high which was $57.14 \%$. The availability of Antimalarial drugs, Artemether/ Lumefantrine tablet, Artesunate Injection, and Artesunate Rectal was fairly high $(57.14 \%)$, low $(42.85 \%)$, and very low (28.57\%), respectively. AZT+3TC+NEV-based ART regimen was available at all surveyed facilities at the time of visit (Table 1). Availability of all antimalarial drugs lay between fairly high to very low according to the WHO availability index (Figure 1).

\section{Utilization of WHO Recommended Medicines for Children Under the Age of}

\section{Five}

Utilization of Oral Rehydration Salt and zinc phosphate for the management of diarrhea were $100 \%$ and 43 (79.63\%), respectively. Only 10 (18.52\%) of Paracetamol dispersible tablet was utilized for pain management, whereas most $44(81.48 \%)$ of pain cases were managed by non-priority medicines like Paracetamol Suppository and Paracetamol Syrup (Figure 2).

About $18.52 \%$ of pneumonia cases were treated by Amoxicillin dispersible tablet, $11.11 \%, 3.70 \%$, and $14.81 \%$ of Pneumonia cases were treated by Ampicillin Injection, Gentamicin Injection, and Ceftriaxone injections, respectively. Surprisingly most 28 (51.85) of the cases were treated by non-priority medicines, such as 
Table 2 Availability of World Health Organization-Recommended Priority Medicines for Children Under the Age of Five on the Day of Visits in Public Health Centers in Gondar Town by 2021

\begin{tabular}{|c|c|c|c|}
\hline \multirow[t]{2}{*}{ Priority Drugs for Children Under the Age of Five } & \multicolumn{2}{|c|}{$\begin{array}{l}\text { Availability at the Day of Visit } \\
N=7\end{array}$} & \multirow[t]{2}{*}{ WHO Availability Index } \\
\hline & Yes & No & \\
\hline Oral rehydration salt Sacket & $6(85.71 \%)$ & I (I4.28\%) & High \\
\hline Zinc Phosphate $20 \mathrm{mg}$ dispersible tablet & $4(57.14 \%)$ & $3(42.85 \%)$ & Fairly high \\
\hline Paracetamol $100 \mathrm{mg}$ dispersible tablet & $6(85.71 \%)$ & $\mathrm{I}(\mathrm{I} 4.28 \%)$ & High \\
\hline Amoxicillin $250 \mathrm{mg}$ dispersible tablet or $500 \mathrm{mg}$ & $5(71.43 \%)$ & $2(28.57 \%)$ & High \\
\hline Ampicillin 250 or $500 \mathrm{mg}$ powder for injection & $4(57.14 \%)$ & $3(42.85 \%)$ & Fairly high \\
\hline Gentamicin sulphate $40 \mathrm{mg} / \mathrm{mL}$ in I $\mathrm{mL}$ Injection & $3(42.85 \%)$ & $4(57.14 \%)$ & Low \\
\hline Ceftriaxone powder I gm/50 mL, or $2 \mathrm{gm} / 50 \mathrm{~mL}$ powder for injection & $4(57.14 \%)$ & $3(42.85 \%)$ & Fairly high \\
\hline Artemether/lumefantrine $20 \mathrm{mg} / \mathrm{I} 20 \mathrm{mg}$ tablet & $4(57.14 \%)$ & $3(42.85 \%)$ & Fairly high \\
\hline Artesunate $110 \mathrm{mg} /$ vial injection & $3(42.85 \%)$ & $4(57.14 \%)$ & Low \\
\hline Artesunate $100 \mathrm{mg}$ rectal capsule & $2(28.57 \%)$ & $5(71.43 \%)$ & Very low \\
\hline Vitamin A: $100,000 \mathrm{IU}$ or $200,000 \mathrm{IU}$ strength capsules & $4(57.14 \%)$ & $3(42.85 \%)$ & Fairly high \\
\hline $\mathrm{AZT}+3 \mathrm{TC}+\mathrm{NVP} 3 \mathrm{TC} 30 \mathrm{mg}+\mathrm{AZT} 60 \mathrm{mg}+\mathrm{NVP} 50 \mathrm{mg}$, dispersible tablet & $7(100 \%$ & $0(0.00 \%)$ & High \\
\hline ABC+ 3 TС 3 TC $60 \mathrm{mg}+120 \mathrm{mg}$ ABC, scored and dispersible tablet & $5(71.43 \%)$ & $2(28.5 \%)$ & Fairly high \\
\hline AZT+3TC $30 \mathrm{mg}+\mathrm{AZT} 60 \mathrm{mg}$, dispersible tablet & $4(57.14 \%)$ & $3(42.85 \%)$ & Fairly high \\
\hline NVP oral syrup, $50 \mathrm{mg} / 5 \mathrm{~mL}(10 \mathrm{mg} / \mathrm{mL})$ & $5(71.43 \%)$ & $2(28.57 \%)$ & Fairly high \\
\hline 3TC $30 \mathrm{mg}$ & $6(85.7 \%)$ & I (I4.28\%) & High \\
\hline LPV/r(LPVI00 mg + Ritonavir 25 mg) & $3(42.85 \%)$ & $4(57.14 \%)$ & Low \\
\hline EVF $200 \mathrm{mg}$, scored tablet. Or $50 \mathrm{mg}$, tablet or capsule & $5(71.43 \%)$ & $2(28.57 \%)$ & Fairly high \\
\hline
\end{tabular}

Cephalexin syrup, Amoxicillin syrup, and trimethoprimsulfamethoxazole syrup (Figure 3).

Malaria case was mainly managed by Artesunate injection $55.55 \%$ followed by Artemether/lumefantrine tablet $37 \%$ and Artesunate rectal $7.41 \%$. AZT +3 TC
+NEV-based regimen was utilized for all first-line cases and LPV/r was utilized only at $2(3.7 \%)$ of surveyed facilities that were on the second-line regimen, the other ART treatment was not utilized despite their availabilities.

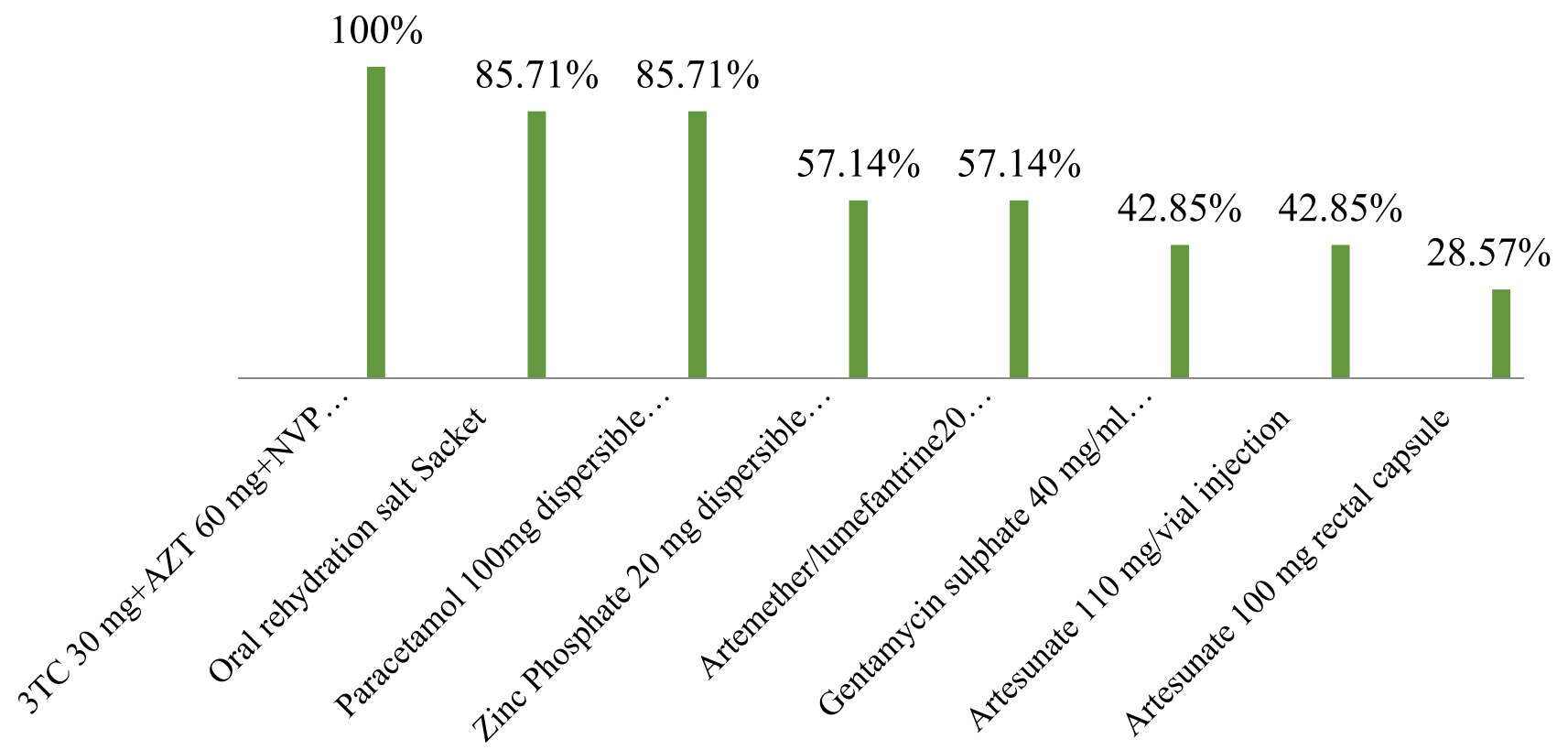

Figure I Availability of World Health Organization-recommended priority life-saving medicines for children under the age of five on the day of visits in public health centers in Gondar Town by 2021 . 


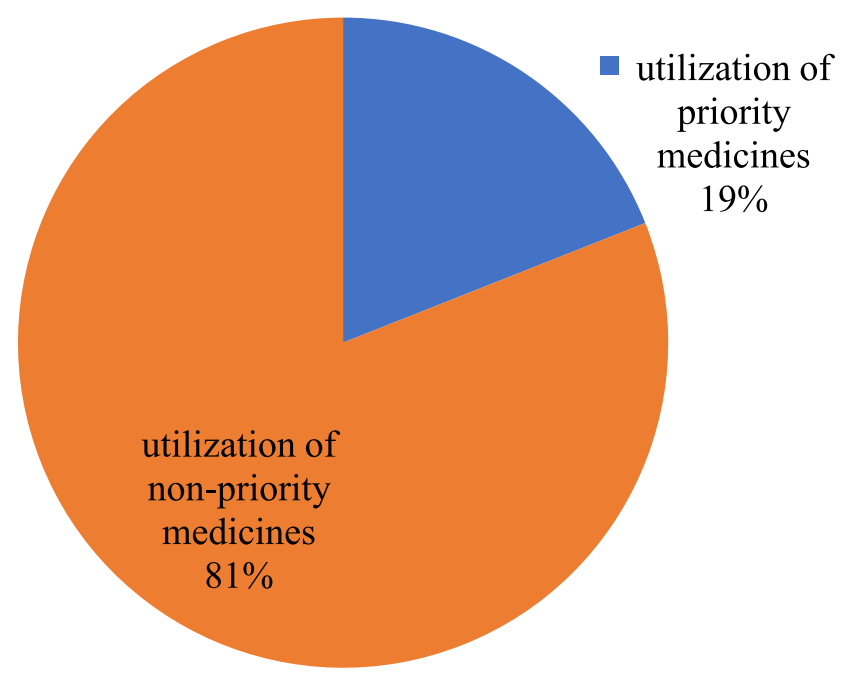

Figure 2 The proportion of utilization of priority and non-priority medicines for pain management for children under the age of five at surveyed facilities in Gondar town, Ethiopia.

\section{Discussion}

Based on the findings of the current study, the overall availability of priority medicines was $62.92 \%$, which was ranged from $28.57 \%$ to $100 \%$, among surveyed facilities. This finding is higher than the study conducted in the western part of Ethiopia on the accessibility of essential medicines for children; the overall availabilities of EMs were below $50 \%$ in both the public sector and private sectors. ${ }^{18}$ The observed difference might be because of better attentions given to priority medicines by supply managers, because the study conducted in the western part includes all essential medicines. The above findings of the current study were also higher than the study conducted in the Tigray region, of Ethiopia, on the Availability and affordability of priority life-saving medicines for children under the age of five, the finding revealed that overall availability was $34.1 \% .^{11}$ Based on this finding, we observed that different results in the same country with the same medical supply sources might be due to Ethiopia essential drug list provide an aggregate list of medications and only focus on systemic classification of medication, not for specific population groups which resulted in there being a different practice at different regions.

The findings of the current study showed that the availability of ORS and Zinc phosphate for the treatments of diarrhea was $85.7 \%$ and $57.14 \%$, respectively. This finding is consistent with a study conducted in Addis Ababa, Ethiopia, on Availability of Lifesaving Maternal and Child Health Commodities and Associated Factors in Public and Private Health Facilities, which found that availability, was $97.1 \%$ and 54.3 for ORS and zinc

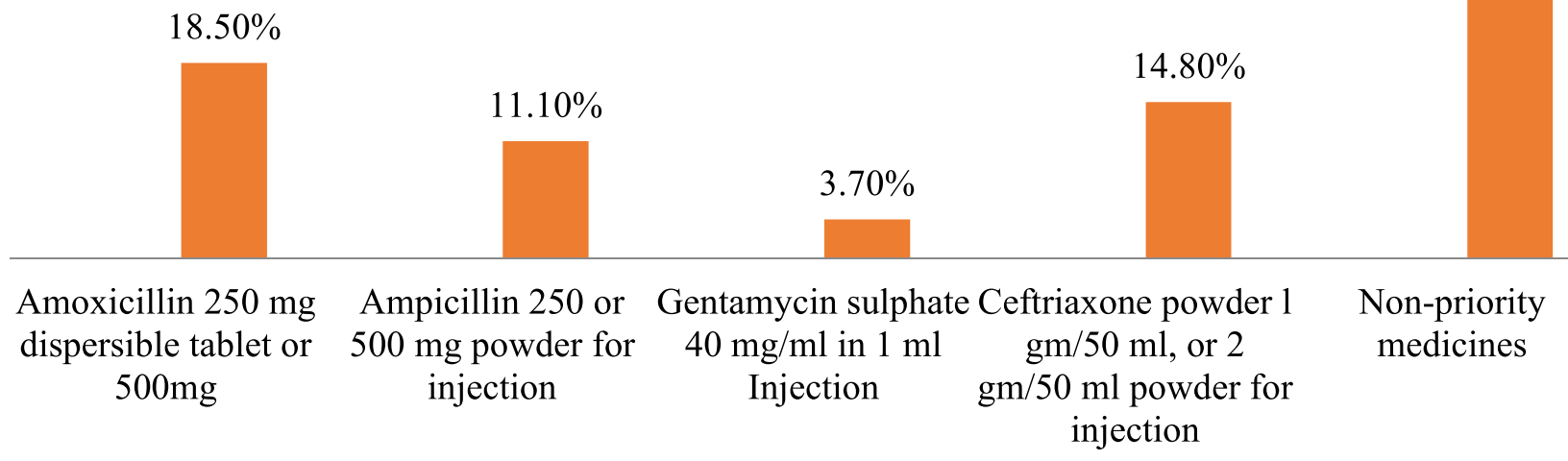

Figure 3 The proportion of utilization of priority and non-priority medicines for the management of pneumonia for children under the age of five at surveyed facilities in Gondar town, Ethiopia. 
phosphate, respectively. The observed similarity was probably because of uniformity in the level of training and the pharmaceutical supply agency of Ethiopia was the common source of medicines for all public sectors. ${ }^{19}$

While the current study's findings were compared to those of a study conducted in Uganda, the current study's utilization of priority medicines for diarrhea was higher (100\% and $76.63 \%$, respectively) for ORS and Zinc phosphate, whereas, in Uganda, utilization for ORS and Zinc phosphate was $20 \%$ and $0 \%$, respectively. ${ }^{1}$

In this survey, the availability of priority life medicines for Pneumonia was $71.43 \%, 57.14 \%, 42.85 \%$, and $57.14 \%$ for Amoxicillin dispersible tablets, Ampicillin injection, Gentamicin injection and Ceftriaxone powder for injection, respectively. This finding was lower than that of a study conducted in northern Ethiopia, in which availabilities were $100 \%, 100 \%, 90 \%$, and $100 \%$ for Amoxicillin dispersible tablet, Ampicillin injection, Gentamicin injection, and ceftriaxone powder for injection, respectively. ${ }^{11}$ However, the current study's findings were higher than those of a Ugandan study, which found $30 \%, 0 \%, 0 \%$, and $20 \%$ availability for Amoxicillin dispersible tablet, Ampicillin injection, ceftriaxone powder for injection, and Gentamicin injection, respectively. ${ }^{1}$ The observed difference might be due to country regions may have a different strategy to tackle the disease.

The availability of Amoxicillin dispersible tablets was also lower in the current study than in a study on the availability of key essential medicines for children conducted in Sri Lanka, in which Amoxicillin was available in $90 \%$ of cases. ${ }^{14}$ The observed difference could be due to countries having different strategies to combat the disease. The low availability of medicines in the appropriate formulations may limit access to medicines to children, which may result in morbidity and moralities which can be treated and prevented by cost-effective essential medications.

Utilization of Amoxicillin dispersible tablet (18.52\%), Ampicillin injection (11.11\%), and Gentamicin injection (3.70\%) which was lower while we were compared with the study conducted in Uganda, utilization was 57\%, 24\%, and 37\% for Amoxicillin, Ampicillin and Gentamicin, respectively. The observed difference might be due to the high utilization of non-priority medicine in the current study, which showed that poor adherence to drug policy, guidelines, and formularies. ${ }^{1}$

According to the findings of the current study, the availability of paracetamol dispersible tablets for pain management was $85.71 \%$, which was greater than the results of a study conducted in northern parts of Ethiopia (80\%. Despite these high availabilities, most of 45 $(83.33 \%)$ the case was treated with non-priority medicines, particularly paracetamol suppositories and paracetamol syrup, this might be because of poor adherence to health workers with WHO guideline and lack of service training about the updated disease management protocol. ${ }^{11}$

The current study revealed that availabilities of Antimalarial medications were $57.14 \%, 42.85 \%$, and $28.57 \%$ for Artemether/lumefantrine tablet, Artesunate injection, Artesunate rectal, respectively. When the results of this investigation were compared to those of a study conducted in the western region of Ethiopia, we discovered that availability was higher for Artesunate injection (42.85\%t) and lower for Artemether/lumefantrine tablet (57.14\%). According to the findings of a study conducted in western Ethiopia, the availability of Artemether/lumefantrine tablet and Artesunate injection was $26.7 \%$ and $66.7 \%$, respectively, for Artemether/lumefantrine tablet and Artesunate injection.

According to the findings of the current study, antimalarial medicine use Artemether/lumefantrine 37\%, Artesunate injection 55.85\%, and Artesunate rectal is $7.41 \%$ which was still higher while we were compared with a study conducted in Uganda, utilization was $0 \%$ for all antimalarial drugs. ${ }^{1}$ The observed difference might be due to countries having different strategies to tackle a disease, and priorities set by the national government may vary from country to country.

Availabilities of Vitamin A in the current study was fairly higher $(57.14 \%)$ while we were compared with the study conducted in western parts of Ethiopia, which was $20 \%$ and $0 \%$ at public and private sectors, respectively. ${ }^{18}$ Availabilities of AZT/3TC/NVP ART regimen was $100 \%$, at all surveyed sectors, the finding of the current study was consistent with the finding of the study conducted in Jimma zone, in which availabilities of AZT/3TC/NVP ART regimen was also $100 \%$, in the current study utilization for this regimen was $96.33 \%$, which is also in line (100\%) with the finding of the study conducted in Jimma zone. In our study $2(3.70 \%)$ of the surveyed cases were on the second-line ART regimen. ${ }^{20}$ The observed similarity of the finding is most probably due to the fact that in Ethiopia, ART drugs are supplied from the common supply source and issued for all public sectors for free.

The study's drawback was that the available data only refer to the availability of a given medicine in a particular 
dosage form and strength on the day of visit at each facility. This may not necessarily reflect the average monthly or annual availability of medicines at the facilities.

\section{Conclusion and Recommendations}

In the present study, the availability and utilization of medication for diarrhea and HIV/AIDS in children under the age of five years were high. However, critical lifesaving drugs for pneumonia and pain management were underutilized in public health centers of Gondar town. WHO-recommended life-saving priority medicines must be integrated into the health logistic unit and essential drug management systems, to increase their availability and utilization. In-service training for health professionals on national and WHO updated treatment guidelines are mandatory to increase the utilization of priority medicines despite their availability.

\section{Abbreviations}

ART, antiretroviral therapy; ABC, Abacavir; HC, health center; EVF, Efavirenz; HIV, human immunodeficiency virus; 3TC, Lamivudine; ORS, oral rehydration salt; LPV/r, Lopinavir/ritonavir; NVP, Nevirapine; SPSS, Statistical Package Software for Social Sciences; TDF, tenofovir disoproxil fumarate; USAID, United States Agency for International Development; WHO, World Health Organization.

\section{Data Sharing Statement}

The datasets used and/or analyzed during the current study are available from the corresponding author on reasonable request.

\section{Ethical Clearance}

The study protocol was approved by an ethical review committee of the School of Pharmacy, University of Gondar and the study was also conducted following the Declaration of Helsinki. The names of patients were not registered in the questionnaire and their unique MRN numbers were locked for confidentiality. Since we used secondary sources, informed consent was waived.

\section{Acknowledgments}

The authors acknowledge the support of the data collectors and all research teams for their unreserved commitment.

\section{Funding}

The authors received no specific funding for this work.

\section{Disclosure}

The authors declare that they have no conflicts of interest for this work.

\section{References}

1. Nsabagasani X, Ogwal-Okeng J, Mbonye A, Ssengooba F, Muhumuza S, Hansen EH. Availability and utilization of the WHO recommended priority lifesaving medicines for under five-year old children in public health facilities in Uganda: a cross-sectional survey. J Pharm Policy Pract. 2015;8(1):1-7. doi:10.1186/s40545015-0038-2

2. Ki-moon HEB. UN commission on commodities for women and commissioners ' report; 2012 September. Available from: https:// www.unicef.org/media/files/UN_Commission_Report_September_ 2012_Final.pdf.

3. Developed E, Group UNI, Estimation CM. Child Mortality 2017; 2017. Available from: https://www.un.org/en/development/desa/popu lation/publications/mortality/child-mortality-report-2017.asp. Accessed August 5, 2021

4. WHO U. Mortality among children under five years of age as a human rights concern. World Health Organ. 2019;22(32):667-700.

5. Mengistie B, Berhane Y, Worku A. Prevalence of diarrhea and associated risk factors among children under-five years of age in Eastern Ethiopia: a cross-sectional study. Open J Prev Med. 2013;03(7):446-453. doi:10.4236/ojpm.2013.37060

6. Qazi S, Aboubaker S, MacLean R, et al. Ending preventable child deaths from pneumonia and diarrhoea by 2025. Development of the integrated global action plan for the prevention and control of pneumonia and diarrhoea. Arch Dis Child. 2015;100(Suppl 1):S23-S28. doi:10.1136/archdischild-2013-305429

7. World Health Organization. Promoting Safety of Medicines for Children. World Health; 2007:59. Available from: https://www.who. int. Accessed August 5, 2021.

8. Bassoum O, Ba A, Tall AB, et al. Availability, management and use of priority life-saving medicines for under-five children in two health districts in Senegal: a cross-sectional study. Health. 2020;12 (2):204-218.

9. Droti B, Neill KPO, Mathai M, Yao D, Dovlo T, Robertson J. Poor availability of essential medicines for women and children threatens progress towards sustainable development goal 3 in Africa. BMJ Glob Health. 2019;4(Suppl 9):1-10. doi:10.1136/bmjgh-2018001306

10. Zewudie AT, Gelagay AA, Enyew EF. Determinants of under-five child mortality in Ethiopia: analysis using Ethiopian demographic health survey, 2016. Int J Pediatr. 2020;2020:1-9. doi:10.1155/ 2020/7471545

11. Abrha S, Tadesse E, Atey TM, et al. Availability and affordability of priority life- saving medicines for under-five children in health facilities of Tigray region, northern Ethiopia. BMC Pregnancy Childbirth. 2018;2:1-9.

12. Medicines WHO. WHO model list of essential medicines for children; 2015; Available from: https://www.who.int/medicines/publi cations/essentialmedicines/18th_EML.pdf. Accessed August 5, 2021.

13. Rahman M, Islam M, Islam M, Sadhya G, Latif M. Disease pattern and health seeking behavior in rural bangladesh. Faridpur Med Coll J. 1970;6(1):32-37. doi:10.3329/fmcj.v6i1.7408

14. Balasubramaniam R, Beneragama BVSH, Ranganathan SS. A national survey of availability of key essential medicines for children in Sri Lanka. Ceylon Med J. 2011;56(3):101-107. 
15. Minstry F, Health OF. National guidelines for comprehensive HIV prevention, care and treatment. Rederal Ninistry Heal; 2017:13-30. Available from: https://differentiatedservicedelivery.org.pdf. Accessed August 5, 2021.

16. USAID | DELIVER PROJECT, Task Order 1. 2008. Logistics Indicators Assessment Tool (LIAT). ArlingtonVa.: USAID DELIVER PROJECT TO 1. Logistics Indicators Assessment Tool (Liat); 2008:1-44. Available from: https://pdf.usaid.gov/pdf. Accessed August 5, 2021.

17. Gelders S, Ewen M, Noguchi N, Laing R. Price, availability and affordability. An international comparison of chronic disease medicines background report prepared for the who planning meeting on the global initiative for treatment of chronic diseases held in Cairo in December 2005; 2006. December 2005. Available from: https:/hai web.org.pdf. Accessed August 5, 2021
18. Sado E, Sufa A. Availability and affordability of essential medicines for children in the Western part of Ethiopia: implication for access. BMC Pediatr. 2016;16(1):1-9. doi:10.1186/s12887-016-0572-3

19. Damtew D, Worku F, Tesfaye Y, Jemal A. Availability of lifesaving maternal and child health commodities and associated factors in public and private health facilities of Addis Ababa, Ethiopia. Health Serv Res Manag Epidemiol. 2019;6:1-9.

20. Tujo TM, Gurmu TG. Availability and utilization of WHO lifesaving medicines for children under five in public health facilities of the Jimma Zone, South West Ethiopia: a cross-sectional survey. Int J Pediatr. 2020;2020:1-10. doi:10.1155/2020/3505672

\section{Publish your work in this journal}

Pediatric Health, Medicine and Therapeutics is an international, peerreviewed, open access journal publishing original research, reports, editorials, reviews and commentaries. All aspects of health maintenance, preventative measures and disease treatment interventions are addressed within the journal. Practitioners from all disciplines are invited to submit their work as well as healthcare researchers and patient support groups. The manuscript management system is completely online and includes a very quick and fair peer-review system. Visit http://www.dovepress.com/testimonials.php to read real quotes from published authors. 